\title{
Political Science 200: Politics and Governance
}

\author{
Frank L. Wilson and William P. McLauchlan, Purdue University
}

This course is designed to introduce you to the concepts and terms needed to understand politics in a changing world. You will find these concepts useful not only in your course work but in becoming informed and (we hope) participating citizens.

An equally important goal is to develop your skills in critical thinking and in expressing your views effectively in written form. These are skills that we hope liberal arts students will develop and use throughout their lives.
Another important objective of this course is to develop an analytic perspective. That means, you should leave with an understanding that there are commonalities among countries, processes, people, behavior, and institutions. Those commonalities are based on observations and empirical evidence, not on ideology or beliefs or desires. As students of Politics and Governance, it is important to find these common features and be able to explain them in terms of evidence and your objective understanding of relationships.
It is essential that you remain current on the assigned readings. The readings are not heavy but you will need to read assignments ahead of time in order to take part in class discussions.

The course will combine both lecture and discussion. Each student is expected to participate in class discussions. While we aspire to scientific knowledge of politics, much of what we will discuss involves opinions. You are expected to develop informed opinions and to defend them in our discussions.

\section{REQUIRED TEXTBOOKS:}

Kay Lawson, The Human Polity, 3rd ed. (Houghton Mifflin, 1993).

Daily subscription to The New York Times-read daily and file for your reference through the course.

The New York Times is also available on the net at http:/www.nytimes.com.

Make it a daily habit to read The Times (London). It is available in the library reading room a few days late. It is available more punctually on the net at http://www.the-times.co.uk.

You should also become regular viewers of C-SPAN.

\section{COURSE REQUIREMENTS AND GRADING POLICY}

\section{- To receive a grade of $\mathrm{C}$ or higher:}

Attend class regularly.

Complete six competency tests with a score of 80 or better.

Competency tests may be taken on-line in the Political Science Data Lab-LAEB 2208. Each test

should take you less than 30 minutes to complete. You should move through the tests sequentially. You may retake the test, if you do not earn a grade of 80 or better, as soon as you feel prepared for such a retake.

- To receive a grade of $B$ or higher:

Attend class regularly.

Complete the six competency tests as above.

Maintain a news journal as described in week 1 .

Complete three of more of the written assignments. Your three papers should include at least one of each type: description, summary, analysis. The net grade on each category of assignment should be positive, e.g., $+1,+2$, etc. For descriptions of the writing projects, see the section on writing assignments.

\section{- To receive a grade of $A$ :}

Attend class regularly.

Complete the six competency tests as above

Maintain a news journal as described in week 1 .

Complete six or more of the written assignments including at least one of each type: description, summary, analysis. The net grades on these assignments should be a positive score of +2 or higher. For descriptions of the writing projects, see the section on writing assignments.

- Important note:

Students may not earn a grade of $\mathrm{C}$ or better in this course if they:

- do not complete the competency tests before the end of the semester 
- do not attend class regularly

- do not contribute regularly to class discussions.

\section{COURSE POLICIES:}

1. Academic honesty. All work for this course must be your own. Anyone guilty of academic dishonesty will fail the course and be reported to the Dean of Students.

2. Attendance. Attendance is mandatory. Your first four absences are "free." After that, each unexcused absence will reduce your course grade by 3 points, e.g., if you have earned a 85 or a B, seven absences will reduce your grade by 9 points to a 76 or a C. Penalties for absences will be assigned based on your overall performance for the semester.

3. Please be sure to retain copies of all materials that you turn in and keep graded assignments should there be a discrepancy in our record keeping. "Lost" papers are your responsibility.

\section{COURSE OUTLINE}

\section{THINKING ABOUT POLITICS}

Week 1 Monday and Wednesday: Introduction to the course

What do we mean by "politics?" How does political science differ from journalism or history? What approaches and methods can be used to study politics? Is the special terminology of political science insightful or simply jargon?

READ: Lawson, pp. 1-53

NEWS JOURNAL: Begin a news journal that includes newspaper articles on an issue of interest to you. For example, the conflict in Bosnia, the US election campaign, the debate over abortion, etc. Each week you should make at least three entries noting coverage of the issue in the NY Times and in the Times (London). Attempt each time to identify underlying themes beyond simply the reporting of daily events. Each entry should be dated.

The first entries of the journal will be due on Monday of the second week of classes. Subsequently, journals should be turned in every two weeks. Your journal should be kept in a separate $81 / 2$ inch $\times$ 11 inch ringed notebook.

\section{THE CONTEXT OF POLITICS}

Week 1 Friday Political Ideologies

Week 2 Monday

Why do people form governments and agree to follow their rules and policies? What is the difference between an ideology and a set of political beliefs? What are the differences between socialism and communism? between liberalism and conservatism? Are ideologies relevant in the post-Cold War world? Are ideologies dead? Are there new ideologies looming in our future?

READ: Lawson, pp. 54-97.

LEARNING ACTIVITY: Write a page-long summary of the ideological underpinnings of one of the following groups:

- National Organization of Women

- Irish Republican Army

- An anti-government U.S. militia group

- Greenpeace

- Amnesty International

- U.S. Chamber of Commerce.

Using the Political Science Data Lab or your own computer, look up the home pages for these 
organizations. Summaries are due on Friday at 5:00 pm. They will form the basis of our class discussion in class on Monday.

Week 2 Wednesday: Political economy

Week 2 Friday

What is the relationship between politics and economics? Does the "pure market" notions of classical economic theory adequately describe the reality of the present? What is a "mixed market?" What is global interdependence?

READ: Lawson, pp. 98-143.

- Gabriel A. Almond, "Capitalism and Democracy," PS: Political Science and Politics September 1991, pp. 467-494

- Charles Lindbloom, Politics and Markets: The World's Political-Economic Systems (1977), pp. 3-13

LEARNING ACTIVITIES:

1. Describe briefly the meaning of "sovereignty" in the past and today. What is meant by "interdependence" and how does it affect sovereignty? These papers are due on Wednesday at 5:00 pm. They will form the basis of our class discussion in class on Friday. (Descriptive paper)

2. Utilizing the SAM computer budget simulation in the Political Science Data Lab, describe the programmatic and fiscal constraints that limit the possibility of balancing the US Budget. (Descriptive paper)

3. Summarize Almond's arguments about the relationship between democracy and capitalism.

${ }^{* *}$ Competency Test 1 Should be Completed by This Time**

Week 3 Monday: Politics and culture

What is a political culture? How is it formed? What factors lead to its change? What is the relation between political culture and the success of a political system? Which is more important, culture or political structures?

READ: Lawson, pp. 144-175.

LEARNING ACTIVITY: Is there a particular set of political values that is required for successful democracy? Be prepared on Wednesday to give a five minute presentation on both sides of this issue. (Descriptive paper)

Week 3 Wednesday: Sociological context

What social factors influence or shape politics? Do these factors also influence the distribution of resources in a society? Can social limits be overcome by political power? How might that happen?

READ: Russell J. Dalton, Citizen Politics: Public Opinion and Political Parties in Advanced Western Democracies 2nd ed. (1996), pp. 165-195.

\section{LEARNING ACTIVITIES:}

1. Identify one demographic (e.g., age, education level), ethnic (e.g., race, religion), or other social factor (e.g. marital status, gender) that affects the political process in a country. Describe its effects on politics in a country of your choice. (Descriptive paper)

2. Summarize Dalton's presentation of the effects of religion on the vote in the US and one other country. (Summary paper)

Week 3 Friday: Politics and the media

How do states and politicians control political communication? Are the media biased toward one or another political belief system?

READ: Lawson, pp. 176-210

- Thomas E. Patterson, "Bad News, Period," PS: Political Science and Politics March 1996, pp. 17-20. 
LEARNING ACTIVITIES: Write on one of the following questions:

1. Describe indications you find or fail to find that the New York Times has a political bias in its news coverage. (Descriptive paper)

2. Summarize the coverage of a single event from last week's news in the New York Times and the Times (London). (Summary paper)

3. After watching C-SPAN coverage of a public meeting or portion of a session of Congress, describe C-SPAN's "open camera" approach that presents news events without commentary. (Descriptive paper)

4. Summarize Patterson's arguments about the effects of "attack journalism." (Summary paper)

\section{Acting in Politics}

Week 4 Monday: The Individual in politics

Week 4 Wednesday

Why do people participate in politics? Do women differ in their patterns of political participation from men? How is voting a political act? What influences the voting decision?

READ: Lawson, pp. 212-245

- Russell J. Dalton, Citizen Politics: Public Opinion and Political Parties in Advanced Western Democracies 2nd ed. (1996), pp. 40-65, 220-237

- Pippa Norris, "Women Politicians: Transforming Westminster?" Parliamentary Affairs 49 (April 1996): 89-102.

\section{LEARNING ACTIVITIES:}

1. Run the "Who votes?" program in the Data Lab. Describe your results and the way those results were obtained, i.e., the kinds of questions asked. (Descriptive paper)

2. Summarize Pippa Norris's arguments on the effect of increased numbers of women MPs on the British House of Commons. (Summary paper)

3. Electronic communications allow the possibility of nearly instantaneous and universal "referendums" on all major policy issues. What are the advantages and disadvantages of such direct participation? If we were to move to such a system in this country, should the results of such direct popular involvement in policy making be binding or only advisory for public officials? (Analysis question)

${ }^{* *}$ Competency Test 2 Should be Completed by This Time**

Week 5 Monday: Organizing for politics: Interest groups

Week 5 Wednesday

Week 5 Friday

Are intermediary groups important in the political system? What is the civil society? How do interest groups seek to influence politics? What is corporatism? What is pluralism?

READ: Lawson, pp. 246-262

- Robert D. Putnam, "Bowling Alone: America's Declining Social Capital," Journal of Democracy 6 (January 1995): 65-78

- The Federalist, No. 10

- Clive S. Thomas, "The American Interest Group System: Typical Model or Aberration?" in Clive S. Thomas, ed., First World Interest Groups: A Comparative Perspective (1993), pp. 27-50. 


\section{LEARNING ACTIVITIES:}

1. Describe three differences between US interest groups and those in other countries. (Descriptive paper)

2. Explain what is meant by "social capital" as discussed by Putnam. (Descriptive paper)

3. Summarize Putnam's explanations for the decline in civil society in the U.S. (Summary paper)

4. Summarize Madison's arguments on curing the mischiefs of faction in Federalist No. 10. (Summary paper)

5. Based on your assessment of effective lobbying, prepare a recommendation to a group that wants to bring congressional action to reduce the complexities of occupational safety laws. Be prepared to present this in class on Friday. (Analysis paper)

Week 6: Organizing for politics: Political parties

Week 7 Monday

Week 7 Wednesday

What is proportional representation? What are the consequences of different electoral systems? What is the part of political parties in building effective and responsive political systems? What is party government? Are parties "in decline?"

READ: Lawson, pp. 232-239 (reread), 263-283

- Russell L. Riley, "Party Government and the Contract with America," PS: Political Science December 1995, pp. 703-707.

LEARNING ACTIVITIES:

1. Describe the proportional representation electoral system. (Descriptive paper)

2. Describe the party system in a country of your choice. (Descriptive paper)

3. Summarize Lawson's discussion of the challenges of internal party democracy. (Summary paper)

4. Discuss the effects of a shift to proportional representation in allocating presidential electoral votes in U.S. presidential elections. (Analysis paper)

5. Analyze the advantages and disadvantages of tight party control over their members' voting in the legislature. Where do you stand on this issue and why? (Analysis paper)

Week 7 Friday: Organizing for politics: Other political organizations

READ: Lawson, pp. 283-291

LEARNING ACTIVITY: Analyze your past or present involvement in a political organizationparty, interest group, community action group. What made your participation worthwhile? What was the key to success or failure in achieving the organization's goals? (Analysis paper)

** Competency Test 3 Should be Completed by This Time **

\section{The Work of Government}

Week 8: Leadership

How do people become political leaders? How do leaders get others to follow them? How do leaders succeed one another?

READ: Lawson, pp. 294-327

- Richard E. Neustadt, "White House and Whitehall," in Anthony Mughan and Samuel C. Patterson, eds., Political Leadership in Democratic Countries (1992), pp. 243-258.

LEARNING ACTIVITY: Select two contemporary American political leaders-one male, one 
female. In a short paper, note any differences you find in their pattern of recruitment, career development, political style, and effectiveness in office. (Analysis paper)

Weeks 9-11: Making the laws

What are the differences between presidential and parliamentary structures? What are the roles of legislatures?

READ: Lawson, pp. 328-361

- Arendt Lijphart, ed., Parliamentary Versus Presidential Government (1992), pp. 1-47, 118-127, 203-206

- Sergio Fabbrini, "Presidents, Parliaments, and Good Government," Journal of Democracy 6 (July 1995): 128-138.

\section{LEARNING ACTIVITIES:}

1. Describe the basic features of a parliamentary system. (Descriptive paper)

2. Summarize the notion of "good government" that Fabbrini uses to evaluate various forms of organizing political institutions. (Summary paper)

3. Some critics of the U.S. pattern of divided government and the resulting stalemate have proposed that the U.S. shift to a parliamentary system. Discuss both the advantages and disadvantages of parliamentary systems in the American context. Be ready to present your ideas in class discussion on Friday. Your preparations should include "talking papers" (i.e., points you wish to cover). (Analytical paper)

4. Evaluate the role of the American Congress in contrast to the role of the House of Commons in Britain. (Analytical paper)

**Competency Test 4 Should be Completed by This Time**

Week 12 Monday: The bureaucracy and the execution of the law

What are the characteristics of administrative bureaucracy? Is bureaucracy inevitable? What are the sources of bureaucratic power? How can the bureaucracy be responsive to popular wishes or demands?

READ: Lawson, pp. 362-393.

\section{LEARNING ACTIVITIES:}

1. The civil service in most countries is considered very powerful. What are the sources of bureaucratic power? (Description paper)

2. Summarize Lawson's discussion of the recruitment of civil servants. (Summary paper)

3. In the U.S. and other countries, the central bank (the Federal Reserve) that controls interest rates and currency creation is largely free from political control. Is this a good or bad thing? Why? (Analysis paper)

4. Identify the final version of an administrative rule published in the Federal Register in the last three months. Outline the authority under which the agency developed the rule, indicate the substance of the rule. Identify the outside participants and interests involved in the rule making, and predict the likelihood that the rule will have the intended effect(s). Write a paper explaining your prediction. (Analysis paper)

Week 12 Wednesday: Judiciary and the law

Week 12 Friday

In what ways do courts make laws? If judges are not popularly elected, how are they held accountable for their actions and decisions? Of what must they be independent in order to function?

READ: Lawson, pp. 394-427

- Martin Shapiro and Alec Stone, "The New Constitutional Politics of Europe," Comparative Political Studies 26 (January 1994): 397-420. 
LEARNING ACTIVITIES:

1. Write a six paragraph summary of Lawson's chapter 12. (Summary paper)

2. Prepare a written summary of the Shapiro and Stone article on constitutional courts in Europe. (Summary paper)

3. The notion of judicial review is a product of the American political experience. However, it is now widely copied in other countries. What are the attractions of a supreme court that is able to review the constitutionality of governmental actions and legislation? What are its potential difficulties? Discuss these issues with reference to one country other than the U.S. in a 3-5 page paper. (Analysis paper)

\section{Alternative Arenas of Government}

Week 13: Local politics and the extraconstitutional exercise of power

What are the advantages and disadvantages of federalism and central rule? What are the fundamental characteristics of a sub-state or inter-state governmental structure? What problems are likely to arise from such a structure? How will those factors affect the operation of the governing system? Why is business so influential in politics? The nature of the division between church and the state? What is the "military-industrial complex?" What is the appropriate role for the military in politics and why is that so often not the case?

READ: Lawson, pp. 428-493

- William Riker, Federalism: Origin, Operation, Significance (1964) pp. 1-48

- Yves Meny and Vincent Wright, eds., Centre-Periphery Relations in Western Europe (1985), pp. 1-32 and one of the following chapters: $2,3,4$, or 5 .

CONSULT: Daniel Elazar, ed., Federal Systems of the World: A Handbook of Federal, Confederal, and Autonomy Relations (1994).

\section{LEARNING ACTIVITIES:}

1. Explain the differences between unitary and federal states. (Descriptive paper)

2. Describe federalism with special attention to the causes that result in federalism. (Descriptive paper)

3. Confederations seem to be experiencing a renewal. What examples of this does Lawson point to? (Summary paper)

4. Describe the sources of the power of business in all types of systems. (Description paper)

5. Summarize the Center-Periphery debate that is outlined in Meny \& Wright, with particular regard to the specific country you have selected to read about in that work. (Summary paper)

6. Summarize Lawson's discussion of the role of religion in politics today. (Summary paper)

7. Describe the merits and disadvantages of unitary states compared to more decentralized states. (Analysis paper)

8. Using one of the federal systems and one of the confederal systems outlined in Elazar, apply Riker's theory of federalism in order to analyze these two governmental systems. Seek to develop explanations for success or failure of the structure given the factors or variables that operate in each of the two countries chosen. (Analysis paper)

9. Centralized government assures equality of government services to all citizens and tends to reduce the likelihood that small minorities will be abused. Explain why this is the case with reference to civil rights in the US or the treatment of Catholics in Northern Ireland. (Analysis paper)

10. During the cold war, international tensions made possible the political influence of the "military-industrial complex." With the cold war over, do you expect the influence of the military-industrial complex to remain or to decrease? Why? (Analysis paper) 
Week 14: International relations

Are there broadly accepted international standards of conduct for nation-states? What supranational governments are there? Do we have a new world order? Should we have one?

READ: Lawson, pp. 494-535

- Ralph Bryant, "Increasing Economic Integration and Eroding Political Sovereignty," The Brookings Review Fall 1994, pp. 42-45

- Michael T. Klare, "The New Challenges to Global Security," Current History April 1993, pp. 155-161.

LEARNING ACTIVITIES:

1. Describe two international organizations such as the UN, the EU, NAFTA, NATO, etc. (Descriptive paper)

2. According to Lawson, what are the sources of international law? (Summary paper)

3. Discuss the advantages and disadvantages of moving toward greater powers for international governments. You may choose to focus on the UN or on the European Union or on the North American Free Trade Agreement (NAFTA). (Analysis paper)

4. The European Union has grown in its powers to the extent that nearly all economic policy for its 15 members is determined in Brussels by the EU institutions rather than by the national governments. Should we now regard the separate nation states of the EU as roughly equivalent to American states and focus our attention on politics at the European level? (Analysis paper)

5. Since the end of the cold war, the UN or other international organizations have intervened or been called on to intervene in a number of civil wars. Briefly outline the criteria you believe should be used to determine when the UN or other international bodies should intervene in "domestic" civil wars. (Analysis paper)

Week 15: The Dynamics of Change

Why does change occur? Is there a trend toward democratization? When is change peaceful? To what extent can political change be controlled?

READ: Lawson, pp. 536-577

- Samuel P. Huntington, The Third Wave: Democratization in the Late Twentieth Century (1991)

- Daniel Patrick Moynihan, Pandemonium: Ethnicity in International Politics (1993), pp. 143-174

- Benjamin R. Barber, "Jihad vs. McWorld," Atlantic Monthly, March 1992, pp. 53-55, 58-63.

The 20th century has been a century of revolution with massive popular rebellions in Russia, China, Mexico, Iran, and elsewhere. Some argue that such mass revolutions are unlikely in the future. Why do they believe that? Does this usher in a new era of peaceful change? Please prepare a 5-page paper on this subject and be ready to discuss it and turn it in on Friday.

${ }^{* *}$ Competency Test 5 Should be Completed by This Time**

\section{Progressive Writing Assignments}

Each of these assignments is relatively short, although different kinds of assignments have different length requirements. At some point in this process you will have developed the ability to prepare lengthy papers, but the first assignments should emphasize brevity and accuracy. Once you have mastered these short, descriptive assignments, you will find that the more elaborate Summaries or Analyses are fairly easy to complete quickly and successfully. You should recognize that, in many instances, long assignments build on your ability to write tight and coherent paragraphs and then organize them logically so that the paper supports the analysis or the point you are trying to make. That clearly builds on the initial writing you are asked to complete in this course.

Types of Writing utilized in this course:

1. Description (perhaps on $3 \times 5$ cards)

In this kind of assignment, you are asked to describe briefly some aspect of a discussion from as- 
signed readings or other sources. This project focuses on conveying an accurate and precise definition of a term, concept, relationship, or set of empirical data from the source. It requires you to put into your own words the best possible definition or description of the item that you can. Be certain to write clearly and carefully. It would probably be valuable if you could write your description a second time, polishing the use of words so that the material you are describing is clearly conveyed. This kind of assignment can often be done on a $3 \times 5$ card. (That indicates the brevity or compactness you should strive to achieve with these assignments.)

2. Summary (perhaps one paragraph in length for each major section of a chapter)

This assignment asks you to summarize, not describe, what an author has written about a subject or topic. This could be applied to a chapter of the text, or to another assigned reading such as a journal article. The value of a summary is that you develop and then write out a statement of the argument or account. To achieve that you clearly must understand those materials.

The ability to summarize a statement or the work of others is a very valuable skill. Such a summary should be succinct and direct. It should explicitly outline the source's thesis, argument, analysis, or explanation depending on the nature of the material. Pay particular attention to material covered in the source; you must understand the material before you can summarize it.
It is important to realize that both of these two assignments do not involve creative, critical, or analytic and original thinking on your part. In that sense, they may appear to be simple. However, to complete these assignments successfully, you need to be able to do small (brief) "portraits" of what others have said about a subject. That requires careful thinking and understanding on your part, and these assignments need to be crafted carefully to be done well.

3. Analysis (perhaps three to five pages in length)

This assignment asks you to convey a sound and comprehensive analysis of a relationship, an argument, or a thesis. This kind of work can be done at any time during the semester, but you will gain analytic perspective and ability throughout the semester and will feel more confident doing analyses later in the semester. Analysis requires you to understand the relevant concepts arguments or variables that are involved. You may have to complete extensive reading or research or carefully re-read materials until you understand the material and can break down the elements of the argument or data analysis and write an organized essay that deals with the components of the subject you are covering. Analysis should display that you have (1) a comprehensive and sophisticated understanding of a concept or relationship or argument, (2) organized the analysis in logical order so that the conclusion and thesis you are presenting is well supported by the paper, and (3) systematically presented an objective analysis in the paper. Clearly, this kind of work requires thinking and creativity on your part.

This kind of writing will be the longest writing assignment you have during this semester. However, you should realize that analysis can involve much longer work than a five-page paper. You are likely to read a number of assigned works that illustrate analysis. These may be 30 to 50 pages in length. The fact that your analytic assignments are to be less than six pages requires that you write them very clearly and tightly, with no excess wordage. You must be sure that each word, sentence, and paragraph in an analytic paper is essential and clearly related to your analysis!

Note: You may revise and resubmit any of your writing assignments for regrading. The purpose of this is to permit students to demonstrate the improvement they have made in the course the semester on any assignment. Your resubmission must be made within one (1) week of the date on which the first paper is graded and returned to you. It should be a clear revision as well as rewrite of the initial assignment. That means you should do more than change words or sentence structure, even though those elements of a writing assignment can improve its quality a good deal. 